\title{
DESENVOLVIMENTO SUSTENTÁVEL NA INDÚSTRIA MOVELEIRA: UM ESTUDO MULTICASO NA REGIÃO NOROESTE DO RS
}

\author{
A. BACKES ${ }^{1}$, M. A. NUSKE ${ }^{2}$, G. C. S. KONRATH ${ }^{3}$, N. J. THESING ${ }^{4}$ \\ ${ }^{1,2} \mathrm{URI}^{3,4}$ Universidade Regional do Noroeste do Rio Grande do Sul \\ amauronuske@gmail.com \\ Submetido 03/03/2017 - Aceito 12/07/2018 \\ DOI: $10.15628 /$ holos. 2018.5697
}

\section{RESUMO}

O estudo desenvolve uma análise sobre como a indústria moveleira com produção seriada da Região Noroeste do Rio Grande do Sul atua quanto às questões ambientais que envolvem a produção e comercialização de seus produtos, objetivando analisar o posicionamento em relação ao desenvolvimento sustentável. Utilizaram-se os métodos de abordagem, dedutivo, qualitativo e quantitativo, através dos métodos de procedimentos: pesquisa exploratória, descritiva, de campo, estudo multicaso e revisão bibliográfica, e como técnicas para coleta de dados o questionário, para análise de dados o software Excel e a análise de conteúdo. Os resultados revelam que existe uma preocupação por parte das empresas quanto ao pleno cumprimento da legislação ambiental pertinente, porém apresentam pouco conhecimento, interesse e ações para o desenvolvimento sustentável. A maioria das empresas não possui assessoria ambiental, e apenas
\end{abstract}

uma empresa tem a própria plantação de árvores e usa energia alternativa para o funcionamento das máquinas. Os resíduos são pouco reaproveitados alternativamente como forma de energia e uso em subprodutos e existem poucos cuidados quanto à poluição do ar. Em $80 \%$ das empresas não se utiliza o marketing verde e $70 \%$ não promovem ou participam de projetos ambientais. As questões ambientais não são consideradas quando é realizado algum investimento na organização, apenas custos e produtividade são avaliados. Conclui-se que as organizações precisam entender que para atingir o desenvolvimento é preciso crescer com sustentabilidade, em harmonia com o meio ambiente e com a comunidade. $O$ retorno de seus investimentos será maior a partir do momento em que proporcionarão boas condições de trabalho aos funcionários e qualidade de vida para a comunidade, atuando com compromisso ambiental e social.

PALAVRAS-CHAVE: Desenvolvimento sustentável, indústria moveleira, Região Noroeste do Rio Grande do Sul.

\section{SUSTAINABLE DEVELOPMENT IN THE MOVING INDUSTRY: A MULTICASE STUDY IN THE NORTHWEST REGION OF RS}

The study provides an analysis of how the furniture industry with serial production in the Northwest region of the State of Rio Grande do Sul acts on environmental issues involving the production and marketing of its products, aiming to analyze the positioning in relation to sustainable development. Deductive approaches, quantitative and qualitative methods were used through the exploratory research procedures, descriptive research, field research, literature review and multi case study, and the survey using such techniques for data collection, and the data analysis and Excel software analysis content. From the research, it appears that there is a concern on the part of companies and to full compliance with the relevant environmental legislation, however, it presents little knowledge, interest and actions for sustainable development. The results reveal that most companies do not have environmental consulting, only one company has own tree plantation (planting trees) and it's using alternative energy to run the machines. The waste is reused alternatively just as a form of energy and used in products and there is little care about the air pollution. $80 \%$ of companies do not use green marketing and $70 \%$ do not promote or participate in environmental projects. Besides all this, environmental issues are not considered when some investment in the organization is done, only costs and productivity are evaluated. Reducing waste, optimizing the use of raw materials, reducing the consumption of energy and water is much more than reducing costs. To do this, organizations need to understand that to achieve the development we must grow sustainably, be in harmony with the environment and the community. The return on investment will be greater from the moment they provide good working conditions for their employees, the quality of life for the community in general, working with social and environmental commitment

KEYWORDS: Sustainable development, furniture industry, the Northwest Region of Rio Grande do Sul. 


\section{INTRODUÇÃO}

Na busca pela sobrevivência, historicamente, a atuação do homem sempre afetou o meio ambiente natural. Durante muitos anos de convivência, homem e natureza viveram em perfeita sintonia, porém com o passar dos anos e a necessidade do desenvolvimento, o meio natural parece impedir para muitos o seu desenvolvimento.

Em um tempo onde o ter parece mais importante que o ser, pessoas fazem e se desfazem das coisas com muita facilidade, tudo é obsoleto, tudo é descartável, tudo está ultrapassado. Para ser o ser humano precisa ter. Necessidades e desejos se confundem em meio a tantas opções. Ferrari (2013) explica que a origem da compulsão pelo ato de comprar está na própria história da humanidade, após a Revolução Industrial, quando, os processos de produção e circulação de bens foram rapidamente difundidos.

A demasiada circulação de bens juntamente com a expansão das capacidades produtivas e o crescimento demográfico mundial evidenciaram que os recursos naturais são limitados, sua escassez e o possível esgotamento ameaçam e comprometem o bem estar das presentes e futuras gerações.

Com o passar dos anos, em virtude de evidentes impactos causados por esta expansão o homem passou a tomar consciência de que a razão dos problemas deveria ser buscada nas formas de desenvolvimento tomadas até então. Em virtude dessa conscientização, lenta, mas, não tardia - pressões são realizadas por grupos organizacionais, consumidores vêm preferindo produtos menos agressivos ao meio ambiente e a Legislação Ambiental vem tornando-se cada vez mais restritiva.

O setor industrial gera diversos resíduos em sua produção na busca de atender seu mercado, para tanto, é necessário que haja um plano de redução, controle, separação, quantificação, reutilização, reciclagem ou descarte adequado destes, cumprindo seu dever perante a legislação pertinente e preservando o meio ambiente, possibilitando bem estar aos funcionários bem como a comunidade.

A luta pelo meio ambiente deve ir além da preservação das matas. Todos os dias, as indústrias emitem grandes quantidades de poluentes ao meio ambiente, resíduos líquidos, sólidos e gasosos. Urge a necessidade de conscientização da população em geral quanto ao seu dever quando se trata do meio ambiente, é preciso que cada um faça a sua parte, reduza, reutilize e recicle, o futuro está baseado das atitudes e escolhas do presente.

Considerando esse contexto, o estudo trata de uma abordagem na indústria moveleira com produção seriada do Noroeste do Rio Grande do Sul em relação ao desenvolvimento sustentável, pois na região citada existem várias indústrias moveleiras que necessitam de grande quantidade de recursos naturais para a obtenção de matéria-prima e, consequentemente, em seu processo produtivo, geram vários resíduos. 


\title{
2 REVISÃO BIBLIOGRÁFICA
}

\subsection{Gestão Ambiental}

Com a intensificação do processo de globalização financeira e produtiva da economia mundial, a partir da década de 1980 os mercados internacionais vêm sofrendo alterações, que aumentam a concorrência global e alteram os padrões de concorrência industrial. Como consequência surgiram normas gerais de padronização de processo, qualidade e gestão ambiental, desta forma as empresas são forçadas a adaptarem-se às exigências dos mercados mais globalizados, afirmam Lustosa, May e Vinha (2003).

No entendimento de Lustosa, May e Vinha (2003), antes do processo de globalização, o comportamento ambiental das organizações era reativo, as empresas tomavam atitudes ambientalmente corretas por obrigação, na maioria das vezes forçadas pela legislação pertinente.

\begin{abstract}
As alterações ocorridas nos mercados internacionais fizeram com que algumas empresas passassem a adotar um comportamento ambiental proativo, ou seja, passaram a adotar práticas menos agressivas ao meio ambiente, algumas se antecipando às regulamentações ambientais ou por meio de implantação da gestão ambiental no âmbito da gestão empresarial (LUSTOSA, MAY e VINHA 2003, p. 167).
\end{abstract}

Harrington e Knight (2001), explicam que as organizações gerenciam sistematicamente suas questões ambientais, integrando-as, frequentemente, à administração global. Identificam os aspectos ambientais e os impactos de suas atividades, produtos e serviços; desenvolvem políticas, objetivos e metas para administrá-los; alocam recursos necessários para uma implantação eficaz; analisam seu desempenho e avaliam suas atividades com vista no aperfeiçoamento.

Seis são os elementos importantes um sistema de gestão ambiental (SGA), segundo Lustosa, May e Vinha (2003):

- Política ambiental: a empresa estabelece suas metas e compromissos com seu desempenho ambiental;

- Planejamento: a empresa analisa o impacto ambiental de suas atividades;

- Implementação e Operação: compreende ao desenvolvimento e a execução de ações para atingir as metas e objetivos ambientais;

- Monitoramento e correção das ações: monitoramento e utilização de indicadores que asseguram que as metas e objetivos estão sendo atingidos;

- Revisão gerencial: SGA é revisado pelo comando superior da empresa, com o objetivo de assegurar sua a propriabilidade, adequação e efetividade;

- Melhoria contínua.

Ainda conforme Lustosa, May e Vinha (2003), existem algumas barreiras na implantação do SGA nas empresas: 
- Organizacionais: sobrevivência da empresa; rotatividade; falta de envolvimento dos funcionários;

- Sistêmicas: falta de informações; sistema de gestão inadequado; falta de capacidade dos empregados;

- Comportamentais: ausência de cultura organizacional; resistência a mudanças; falta de lideranças; insegurança no trabalho;

- Técnicas: falta de infraestrutura; treinamento limitado; defasagem tecnológica; acesso limitado às informações técnicas;

- Econômicas: disponibilidade de recursos e custo de financiamento; exclusão de custos ambientais da tomada de decisão e das análises de custo/benefício;

- Governamentais e outras: política ambiental; falta de incentivo para minimizar os impactos ambientais; falta de suporte institucional, falta de espaço físico.

\subsection{Legislação Ambiental}

A legislação é um instrumento que regulamenta as ações do homem, pessoa física e jurídica, punindo atitudes não condizentes.

Cunha e Guerra (2010) argumentam que:

Assim é que pela própria evidência dos elementos integrantes do meio ambiente, o conteúdo e o alcance da legislação ambiental protecional correlata ora integram normas, notadamente do Direito Urbanístico, com sua legislação de uso e ocupação do solo, do Código Florestal, das Leis de Proteção da Fauna e da Flora, do Código de Águas com legislação complementar, ora se relacionam, direta ou indiretamente, com normas do Estatuto da Terra (Código Rural), do Código de Mineração, do Código Civil (Direito das Coisas - Direito da Propriedade), do Código da Saúde Pública, do Código de Defesa do Consumidor, Código Tributário, Código Penal, Direito Administrativo, Direito Econômico, dentre outros ramos do Direito. (p. 190-191).

Milaré (1993) apud Cunha e Guerra (2010), destaca que existem três marcos importantes da resposta recente que o ordenamento jurídico tem dado ao clamor social pela imperiosa tutela do meio ambiente. O primeiro marco foi a edição da Lei no. 6.938, de 31/08/1981; o segundo foi a promulgação da Lei no 7.347, de 24/07/1985; e a edição da nova Constituição Federal de 05/10/1988.

De acordo com Cunha e Guerra (2010), a Lei Federal no. 6.938, de 31/08/1981 “dispõe sobre a política Nacional do Meio Ambiente, seus fins e mecanismos de formulação e aplicação, e dá outras providências".

Cunha e Guerra (2010, p.194) afirmam que a Lei Federal no 7.347, de 24/07/1985 disciplina a ação civil pública de responsabilidade por danos causados ao meio ambiente, ao consumidor, a bens e direito de valor artístico, estético, histórico, turístico e paisagístico (vetado), e dá outras providências. 
Ainda conforme Cunha e Guerra (2010), esta lei veio disciplinar a ação civil pública como um instrumento processual específico para a defesa do meio ambiente, tornando desta forma a agressão ambiental um caso de Justiça e que também pudesse ser proposta pelas ações civis.

Para Cunha e Guerra (2010), a partir do advento da Constituição Federal do Brasil, de 05/10/1988, a questão ambiental passou a ter relevo especial no Brasil. Por meio de diversos ordenamentos jurídicos, o Brasil tem avançado no sentido de encontrar soluções para a degradação o meio ambiente, em busca de ajustar o direito clássico com a realidade antes tão distante e desconhecida.

\subsection{ISO 14000}

No entendimento de Barbieri (2007) a International Organization for Standardization ISO, criada em 1947, é uma instituição constituída por órgãos internacionais de normalização com o objetivo de desenvolver a normalização e atividades relacionadas para facilitar as trocas de bens e serviços no mercado internacional e a cooperação entre os países nas esferas científicas, tecnológicas e produtivas.

Reis (1995) apud Seiffert (2011, p. 15), explica que o SGA apresenta-se como um processo estruturado que possibilita a melhoria contínua, num ritmo estabelecido pela organização de acordo com suas circunstâncias, inclusive econômicos.

Seiffert (2011) destaca que:

Além do estabelecimento de uma forma de ação comum para o gerenciamento ambiental, as normas ISO 14000 são uma resposta às exigências legais e do mercado. Tais exigências guardam relação direta com as possibilidades de atuação que se abrem às organizações. O acesso ao mercado e ao lucro é cada vez maior para as empresas que não poluem, deixam de poluir ou o fazem em menor escala. O raciocínio inverso é válido para empresas que não gerenciam seus riscos ambientais, tentando assim maximizar seus lucros através da socialização dos prejuízos ambientais (p. 10).

De acordo com Barbieri (2007), no ano de 1991, um grupo de acessória denominado Strategic Advisory Group on the Environment - SAGE foi criado para estudar os impactos de normas ambientais sobre o comércio internacional. No final no ano de 1992, o SAGE recomendou a criação de um comitê específico para a elaboração de normas sobre gestão ambiental.

Barbieri (2007) orienta que "um sistema de gestão empresarial (ISO 14001 e ISO 14004) é um conjunto de atividades administrativas e operacionais inter-relacionadas para abordar os problemas ambientais atuais ou para evitar o seu surgimento" (p. 153).

Ainda conforme Barbieri (2007), a avaliação do ciclo de vida (ISO 14040 E ISO 14044) é um instrumento de gestão ambiental aplicável a bens e serviços. O que interessa para a gestão ambiental são os aspectos ambientais de um bem ou serviço em todos os estágios, desde a origem dos recursos no meio ambiente até sua disposição final dos resíduos de materiais e energias após o uso. 


\subsection{Produção mais limpa e ecoeficiência}

Nos últimos anos do século $X X$ o aspecto mais importante da gestão ambiental empresarial é a gradativa compreensão de que a adoção de medidas que objetivam a maior eficiência na prevenção da contaminação é muito mais vantajosa não só do ponto de vista de evitar problemas ambientais, mas porque resultam em aumento da competitividade das organizações.

No entendimento de Dias (2007), entre os conceitos mais discutidos pelas organizações empresariais internacionais e nacionais estão os conceitos de Produção Mais Limpa e Ecoeficiência que inter-relacionados constituem mecanismos que complementam e fortalecem os Sistemas de Gestão Ambiental nas organizações.

Segundo Barbieri (2007), posteriormente a Organização das Nações Unidas para o Desenvolvimento Industrial - ONUDI, formulou um conceito de Desenvolvimento Industrial Ecologicamente Sustentável - DIES: “[...] modalidades de industrialização que promovem as vantagens econômicas e sociais das gerações presentes e futuras sem comprometer os processos ecológicos básicos" (p. 135).

Dias (2007), explica que a produção mais limpa adota os seguintes procedimentos:

- Processos de Produção: conservação da matéria-prima e energia, eliminando substâncias tóxicas e reduzindo a quantidade e a toxicidade de todas as emissões e resíduos.

- Produtos: redução dos impactos negativos ao longo de todo o ciclo de vida do produto.

- Serviços: preocupações ambientais no projeto e fornecimento de serviços.

Para Dias (2007), as estratégias de Produção Mais Limpa são resultado de mudanças no enfoque da abordagem na questão ambiental, antes o foco era o controle da contaminação e hoje o foco é a prevenção.

De acordo com o Programa das Nações Unidades para o Meio Ambiente - PNUMA apud Dias (2007), o programa para a produção mais limpa busca:

- Aumentar o consenso mundial para uma visão de produção mais limpa.

- Apoiar a rede de organizações dedicadas à promoção de estratégias de produção mais limpa e à ecoeficiência.

- Ampliar as possibilidades de melhoria ambiental das empresas mediante a capacitação e a educação.

- Apoiar projetos que sirvam de modelo de referência.

- Fornecer assistência técnica.

Com o propósito de alcançar estes objetivos o Programa para a Produção Mais Limpa concentra-se em duas linhas, a difusão da informação e a capacitação. Como instrumentos de apoio a esses objetivos existem, nos mais diversos países em desenvolvimento que atuam em conjunto com a Organização das Nações Unidas para o Desenvolvimento Industrial, os Centros Nacionais para a Produção Mais Limpa, afirma Dias (2007). 
Apesar da produção mais limpa e da ecoeficiência possuírem características comuns, existem algumas diferenças entre esses dois modelos de gestão. Barbieri (2007), afirma que a reciclagem interna e externa é muito valorizada pela ecoeficiência, diferentemente da produção mais limpa, na qual essa opção está em segundo e terceiro níveis. A preocupação com os produtos na produção mais limpa decorre basicamente da necessidade de prevenir a poluição durante o processo produtivo, já a ecoeficiência preocupa-se também com o produto em si e seus impactos ambientais.

\title{
2.5 Sustentabilidade
}

Albuquerque (2009) explica que a palavra sustentabilidade vem do latim sustentare, que significa suster, suportar, ou seja, a possibilidade de uma organização garantir a sua continuidade e perenidade.

Veiga (2010) acredita que:

\begin{abstract}
Há um novo requisito que exige ajustes em ultrapassadas concepções do desenvolvimento: a sustentabilidade do crescimento e da melhoria da qualidade de vida. Trata-se de um imperativo global que chegou para ficar, em virtude da percepção de que a biosfera, em níveis global, regional, nacional e local, está sendo submetida a pressões insuportáveis e prejudiciais para o próprio desenvolvimento e as condições de vida. Como diz Sunkel (2001: 295), "este é um tema que as classes dirigentes da nossa região não poderão adiar sob pena de sofrer graves conflitos internos e sérias dificuldades internacionais". (p. 187).
\end{abstract}

Goldsmith et al. (1972) apud Albuquerque (2009) define que a sociedade é sustentável quando todos os seus objetivos e intenções podem ser atingidas indefinidamente, fornecendo satisfação aos membros envolvidos.

Philippi (2001), conceitua a sustentabilidade como a capacidade de se autosustentar, auto manter. Uma atividade sustentável é aquela que pode ser mantida por um longo período indeterminado, para sempre, de forma a não se esgotar nunca, apesar dos imprevistos que podem ocorrer durante este período. É possível aplicar o conceito de sustentabilidade a uma sociedade que não coloca em risco os recursos naturais como ar, água, solo e a vida vegetal e animal dos quais a vida depende.

Para Sachs (2004) apud Veiga (2010):

A sustentabilidade ambiental é baseada no duplo imperativo ético de solidariedade sincrônica com a geração atual e de solidariedade diacrônica com as gerações futuras. Ela compele a trabalhar com escalas múltiplas de tempo e espaço, o que desarruma a caixa de ferramentas do economista convencional. Ele impele ainda a buscar soluções triplamente vencedoras (Isto é, em termos sociais, econômicos e ecológicos), eliminando o crescimento selvagem obtido ao custo de elevadas externalidades negativas, tanto sociais como ambientais. Outras estratégias, de curto prazo, levam ao crescimento ambientalmente destrutivo, mas socialmente benéfico, mas socialmente destrutivo. ( $p$. 171-172). 
Na visão de Munasinhe e Mcneely (1995) apud Albuquerque (2009) a sustentabilidade refere-se à obtenção de um conjunto de indicadores que se referem ao bem-estar e que possam ser mantidos ou que cresçam no tempo.

\subsection{Desenvolvimento Sustentável}

No entendimento de Smaneoto (2012) o homem é um hóspede/passageiro da terra e deveria ter consciência disso. No entanto, retira de forma gananciosa tudo o que pode e transforma em produto de venda e consumo. A ideia de uma sociedade sustentável é essencial para repensar as práticas do dia-a-dia e os grandes valores da vida, necessariamente uma sociedade sustentável exige uma mudança de comportamento.

O enfoque proposto pelo documento Nosso Futuro Comum, Relatório de Brundtland, desenvolvido pela Comissão Mundial sobre Meio Ambiente e Desenvolvimento em 1991, o desenvolvimento sustentável é aquele que atende as necessidades presentes sem comprometer a capacidade das gerações futuras atenderem também as suas necessidades.

Satisfazer as necessidades e as aspirações humanas é o principal objetivo do desenvolvimento. Nos países em desenvolvimento, as necessidades básicas de grande número de pessoas - alimento, roupas, habitação, emprego - não estão sendo atendidas. Além dessas necessidades básicas, as pessoas também aspiram legitimamente a uma melhor qualidade de vida. Para que haja um desenvolvimento sustentável, é preciso que todos tenham atendido as suas necessidades básicas e lhes sejam proporcionadas oportunidades de concretizar suas aspirações a uma vida melhor (PHILIPPI, 2001, p. 304).

Lustosa, May e Vinha (2003) chamam a atenção para o fato de que o conceito de desenvolvimento sustentável surgiu em 1970, num contexto de debate sobre as relações entre crescimento econômico e meio ambiente. Ele emerge desse contexto como uma posição conciliadora, onde se reconhece que o progresso técnico efetivamente relativizava os limites ambientais, mas não os eliminava, e que o crescimento econômico é condição necessária, mas não suficiente para a eliminação da pobreza e disparidades sociais.

Para Vorholz (2012):

Sustentável, é um desenvolvimento "que satisfaz as necessidades da atualidade, sem o risco de que as gerações futuras não possam satisfazer suas próprias necessidades". Esta fórmula, propagada pela comissão que recebeu o nome da antiga primeira-ministra norueguesa Gro Harlem Brundtland, fundamentou o consenso. Isto só foi possível porque o ser humano estava a ponto de destruir realmente, a olhos vistos, as suas condições de vida. "Vivenciamos uma instauração das desigualdades entre e no interior das nações, um agravamento da pobreza, da fome, da doença e do analfabetismo, bem como a destruição contínua dos sistemas ecológicos, dos quais dependem o nosso bemestar" (p. 26).

Na visão de Dias (2007), o desenvolvimento sustentável nas organizações apresenta três dimensões: econômica, social e ambiental. 
Dias (2007), afirma que do ponto de vista econômico a organização deve ser economicamente viável. Seu papel na sociedade deve ser cumprido considerando o aspecto da rentabilidade, em outras palavras, dar retorno ao investimento realizado pelo capital privado.

Munasinghe (2007) apud Albuquerque (2009) menciona que a dimensão econômica tem por objetivo o bem estar humano por meio da produção e consumo de bens e serviços.

Sachs (1993) apud Albuquerque (2009) argumenta que a dimensão econômica busca possibilitar uma gestão mais eficiente dos recursos e um fluxo regulador dos investimentos públicos e privados. Esta dimensão busca reduzir os custos sociais e ambientais.

Dias (2007), explica que do ponto de vista social, a organização deve satisfazer aos requisitos de proporcionar as melhores condições de trabalho aos seus empregados, procurando contemplar a diversidade cultural existente na sociedade em que atua. Além disso, seus gestores devem participar ativamente das atividades socioculturais de expressão da comunidade que vive no entorno da unidade produtiva.

A Global Reporting Intitive - GRI (2007) apud Albuquerque (2009) orienta que a dimensão social refere-se aos impactos da organização nos sistemas sociais nos quais opera, tais como, práticas trabalhistas, direitos humanos, sociedade e responsabilidade pelo produto.

Para Sachs (1993) apud Albuquerque (2009), a dimensão social busca consolidar um processo de desenvolvimento baseado na visão do que é uma boa sociedade.

Do ponto de vista ambiental, a organização tem o dever de pautar-se pela ecoeficiência dos seus processos produtivos, adotar a produção mais limpa, oferecer condições para o desenvolvimento de uma cultura ambiental organizacional, adotar uma postura de responsabilidade ambiental, buscando a não contaminação de qualquer tipo de ambiente natural, e procurar participar de todas as atividades patrocinadas pelas autoridades governamentais locais e regionais no que diz respeito ao ambiente natural, afirma Dias (2007).

Munasinghe (2007) apud Albuquerque (2009) alerta que a dimensão ambiental deve preocupar-se com a viabilidade e a saúde de sistemas vivos, através da conservação do vigor, a capacidade do sistema de voltar ao seu equilíbrio após receber um choque e organização destes.

Nessa perspectiva, Romeiro (2012) afirma que o conceito mais recente de desenvolvimento sustentável como economia verde incorpora a necessidade de adoção de parâmetros de sustentabilidade tendo em conta o risco ambiental. Em relação ao suposto "tradeoff" entre crescimento econômico e meio ambiente, reafirma-se sua inexistência, reforçando principalmente os argumentos que justificam essa premissa com base em expectativas sobre os avanços na geração de tecnologias triplamente ganhadoras: social, econômica e ambiental.

$\mathrm{Na}$ linha de pensamento de Seiffert (2011), o desenvolvimento sustentável estabelece que o atendimento às necessidades do presente não pode comprometer a capacidades das futuras gerações atenderem suas necessidades.

\subsection{Marketing Verde ou Ecológico}


Souza (1993) apud De Andrade, Carvalho e Tachizawa (2007) explica que as estratégias de marketing adotadas pelas empresas estão sendo moldadas com o objetivo de melhorar a imagem através da criação de novos produtos "verdes" de ações voltadas a proteção ambiental.

Dias (2007) afirma que:

\begin{abstract}
Essa vertente do marketing, envolvida com as necessidades recentes do cliente-cidadão consciente da importância da preservação da natureza, tem assumido várias denominações, entre as quais: marketing ecológico, verde ou ambiental; todas elas têm como preocupação fundamental as implicações mercadológicas dos produtos que atendam às especificações da legislação ambiental e que contemplam as expectativas de uma boa parcela de consumidores, no que diz respeito a não serem agressivos ao meio ambiente (p. 140).
\end{abstract}

Dias (2007) chama a atenção que em virtude do aumento da consciência ambiental da população mundial, surge um novo tipo de consumidores, chamados de verdes, ecológicos ou então ambientalmente conscientes. Esses novos consumidores manifestam preocupações ambientais em seu comportamento de compra, buscando produtos que causam o menor impacto negativo possível ao meio ambiente, eles compreendem que o valor agregado e traduzido como aumento no seu preço significa aumento no seu valor social, desta forma valorizam empresas ambientalmente responsáveis e manifestam repúdio em relação às empresas que contaminam o meio ambiente. Esse novo comportamento do consumidor traz a necessidade das empresas abordarem o marketing sob um ponto de vista ecológico.

A necessidade das organizações adotarem estratégias de marketing voltadas a preservação ambiental ganha força através de movimentos que consumidores ambientalmente conscientes realizem em prol de produtos ambientalmente corretos.

\title{
3 METODOLOGIA
}

Para Pinheiro (2010) o estudo da metodologia envolve métodos que identificam os meios utilizados para alcançar os objetivos indicados no trabalho a ser desenvolvido, esclarecendo a forma como o estudo será realizado.

Entende-se a metodologia como a descrição detalhada e rigorosa dos procedimentos de campo ou laboratório utilizados. Bem como dos recursos humanos e matérias envolvidos, do universo de pesquisa, dos critérios para seleção da amostra, dos instrumentos de coleta, dos métodos de tratamento dos dados dentre outros fatores envolvidos.

Neste estudo foram utilizados os seguintes métodos de abordagem: dedutivo, objetivando analisar a percepção das indústrias moveleiras da Região Noroeste do Rio Grande do Sul diante o desenvolvimento sustentável; qualitativo, empregado para examinar e refletir sobre as percepções dos gestores das indústrias moveleiras, para assim, obter dados quanto seu posicionamento diante o desenvolvimento sustentável; e quantitativo que foi utilizado para analisar as questões de múltipla escolha que compunham o questionário.

Os procedimentos utilizados foram: a pesquisa exploratória, a fim de sustentar a busca de informações e opiniões, além de promover esclarecimentos acerca do tema; pesquisa descritiva, pois os dados obtidos não sofreram interferência do autor, este apenas analisa e interpreta a 
opinião dos gestores pesquisados a respeito do tema do estudo; pesquisa de campo onde foram coletadas informações junto aos gestores de indústrias moveleiras com produção seriada da Região Noroeste do Rio Grande do Sul, por meio de um questionário, composto por 18 questões as empresas responderam sobre o porte, área de atuação, público-alvo de seus produtos, questões relacionadas ao desenvolvimento sustentável, como a forma de obtenção da matériaprima, seu armazenamento, energia das máquinas, a luminosidade no local, destinação dos resíduos gerados em seus processos produtivos, mudanças ocorridas com a legislação ambiental e atividades realizadas em prol do meio ambiente. A pesquisa foi realizada entre 11 de março a 12 de abril de 2013, possibilitando um melhor entendimento sobre a visão da Indústria Moveleira com produção seriada do Noroeste Gaúcho em relação ao Desenvolvimento Sustentável. O estudo caracterizou-se como multicaso, pois o questionário foi enviado via e-mail para 17 indústrias moveleiras com produção seriada da Região Noroeste do Rio Grande do Sul, a qual é composta por 75 municípios, destas 10 o responderam. Também utilizada, a revisão bibliográfica por meio de contribuições de diversos autores através de livros, artigos e sites com o intuito de ampliar o conhecimento sobre o tema e aprimorar o estudo. Para a analise dos dados obtidos foi utilizada a análise de estudo e o software Excel para analisar as respostas abertas e fechadas que constituíram o questionário.

\section{RESULTADOS E DISCUSSÕES}

A pesquisa evidenciou que $60 \%$ das empresas possuem assessoria ambiental e $40 \%$ não possuem. A assessoria ambiental contribui de forma significativa para o desenvolvimento da organização, pois a orienta quanto aos aspectos da legislação pertinente e à adoção de medidas preventivas para evitar contravenções e consequentemente punições. Se a organização não possui assessoria ambiental própria ou prestada por terceiros é importante capacitar funcionários da empresa para realizarem esta atividade. Salienta-se que a conscientização ambiental deve acontecer do nível estratégico ao operacional.

Verificou-se que nenhuma organização possui a certificação da ISO 14000 e não a está implantando. A ISO certifica que a empresa adota um SGA, desta forma possui procedimentos de controle ambiental, estes são registrados e divulgados aos órgãos de controle ambiental bem como para o mercado e a sociedade. Com a certificação a empresa demonstra que se preocupa com as questões ambientais além de proporcionar redução de desperdícios e custos. O custo que a empresa terá para implementar a ISO, dependerá muito de cada empresa, pois empresas bem estruturadas que têm o pensamento voltado a questões ambientais e adotam práticas que visam a preservação ambiental não terão muito para alterar, outras, com pouca estrutura, necessitam de mais investimentos, desde treinamento de pessoal até aquisição de equipamentos.

Os benefícios com a implantação da ISO 14000 são muitos, tanto para empresas como para clientes. As empresas asseguram que cumprem a legislação pertinente, reduzem os riscos de acidentes ambientais, o desperdício de matéria-prima e resíduos além de obter o reconhecimento da sociedade e de clientes. Já os benefícios concebidos aos clientes são que eles podem confiar no produto que estão adquirindo e que estão contribuindo para a preservação ambiental, já que a empresa age e é fiscalizada quanto à preservação. 
A Lei no 9.921, de 27 de julho de 1993 Art. 8o, EMATER (2013), orienta que a coleta, o transporte, o tratamento, o processamento e a destinação final dos resíduos sólidos de estabelecimentos industriais, comerciais e de prestação de serviços, inclusive de saúde, são de responsabilidade da fonte geradora independentemente da contratação de terceiros, de direito público ou privado, para execução de uma ou mais dessas atividades.

Desta forma, a pesquisa evidenciou que os resíduos sólidos da indústria moveleira, são na maioria dos casos (6) destinados para descarte por terceiros, outros descartam em aterros e reaproveitam para a produção de subprodutos (3) e apenas uma empresa utiliza resíduos no uso de energia em caldeiras. O uso de resíduos sólidos como o pó da madeira, do MDF, MDP ou aglomerado em caldeiras na própria empresa é uma alternativa sustentável, pois ao mesmo tempo em que gera energia alternativa e reduz o consumo de energia elétrica, a empresa também contribui não passando adiante um resíduo gerado por ela mesma. É importante destacar quanto ao uso de resíduos sólidos, que de acordo com a Fundação Estadual de Proteção Ambiental (FEPAM), Portaria № 009/2012 Art. $2^{\circ}$, PROAMB (2013) Materiais derivados de MDP, MDF e assemelhados, na forma de cavacos, serragem, pó de lixamento, aglomerado, compensado e demais derivados poderão ser utilizados como combustível em processo de geração de calor por combustão externa, em caldeiras e fornos nos quais a temperatura mínima na zona de queima seja superior a 750 C, desde que não tenham sido tratados com produtos halogenados, anti fungicos, tintas, vernizes, adesivos e revestidos de plásticos, PVC ou quaisquer outros revestimentos, exceto papel melamínico puro.

Outra forma de dar um destino sustentável aos resíduos de madeira, MDF, MDP e aglomerado é formar parcerias com os fornecedores e realizar o reenvio dos resíduos para a fabricação de novas chapas. Uma empresa, ISTOEDINHEIRO (2013), fabricante de chapas para a indústria moveleira aposta nesta ideia, pois utiliza como matéria-prima, resíduos resultantes do processo mecânico de serrarias e laminadoras, como serragem, cavacos e até mesmo o pó de madeira, há orientação da empresa para a sustentabilidade, tanto em relação às tecnologias empregadas quanto aos padrões de produtos ofertados ao mercado brasileiro.

A orientação da NR 25 - Resíduos Industriais, 25.3.2, PORTAL MTE (2013), é de que os resíduos líquidos e sólidos produzidos por processos e operações industriais devem ser adequadamente coletados, acondicionados, armazenados, transportados, tratados e encaminhados à adequada disposição final pela empresa. A pesquisa demonstra que $10 \%$ das empresas cometem crime ambiental, pois descartam os resíduos líquidos sem tratamento.

Os cuidados quando a poluição do ar também foram abordados no estudo, que evidenciou que todas as empresas possuem exaustor instalado e apenas duas afirmaram possuir células de pintura fechadas. $O$ uso de célula de pintura fechada, além de impedir que ciscos ou poeiras presentes no ambiente caiam sobre as peças causando retrabalho e os resíduos de tinta pulverizada no processo de pintura sejam dispersos no ambiente poluindo o ar, também previnem danos a saúde de todos os funcionários da organização, pois os funcionários que trabalham no setor de pintura utilizam um tipo de Equipamento de Proteção Individual (EPI) com maior proteção para o sistema respiratório devido sua exposição, já os demais utilizam outro tipo. 
Analisando os resultados da pesquisa constatou-se que todas as empresas utilizam energia elétrica para a iluminação do local, outras formas utilizadas por algumas empresas são portas basculantes, paredes com partes de vidro e telhados transparentes. Alternativas que reduzem o uso de energia elétrica e que não diminuem a luminosidade do local são adotar telhados de vidro e cores claras na parede, de preferência branco o que permite o uso de lâmpadas menos potentes reduzindo o consumo de energia elétrica.

Adotar medidas de classificação dos produtos na armazenagem facilita a localização do material e evita que este fique esquecido em local inadequado e faça falta na produção. De acordo com a pesquisa, apenas quatro empresas separam os produtos por grupo para armazenálos, sugere-se às outras empresas adotarem esta prática, pois assim terão um padrão na empresa, onde cada grupo terá um local específico e adequado para sua alocação.

Outra informação relevante coletada é de que apenas $20 \%$ das empresas utilizam o marketing verde na divulgação de sua marca e seus produtos. Os consumidores estão cada vez mais conscientes quanto às questões ambientais e exigem produtos ambientalmente corretos. Uma proposta para as empresas é o uso de selos verdes em seus produtos, referindo-se que adotam sistemas de produção que otimiza o uso da matéria-prima, que emitem menos resíduos e que promovem ou participam de projetos ambientais, ressaltando que é de suma importância adotar estas práticas antes de utilizar selos verdes como marketing.

Os consumidores buscam móveis versáteis de qualidade e inovação, o ecodesign ${ }^{1}$ surge como um diferencial, pois projeta móveis práticos e úteis que tem uma vida útil maior, móveis que minimizam os impactos ambientais. Sugere-se às empresas, adotarem o ecodesign em seus projetos e trabalharem com seus clientes o fato de estarem produzindo móveis com consciência ambiental.

Em relação à participação em projetos ambientais, 70\% das empresas afirmam não participar. Evidencia-se que é preciso que as empresas se engajem em prol do meio ambiente, se insiram em projetos ambientais formando parcerias com o poder público, escolas e a comunidade para juntos promoverem ações de preservação, concursos de melhores práticas ambientais e elaboração de projetos inovadores em suas cidades, que sirvam de exemplo para outras empresas e cidades.

Sugere-se as empresas, incentivar a Rede INDUMÓVEIS, para que esta promova reuniões e debates relacionados às práticas ambientais, formas de desenvolver sustentavelmente o setor e promover ações na região, com o objetivo de ressaltar a importância de tudo que diz respeito à preservação do meio ambiente, separação do lixo, preservação e plantio de áreas verdes, conservação da água e solo.

Percebe-se no decorrer da análise que as indústrias apresentam uma tímida preocupação ambiental em suas atividades, porém, em sua maioria, não há consciência ambiental, pois quando são realizados investimentos na organização, seja em máquinas, tecnologias ou pessoas

\footnotetext{
${ }^{1}$ Ecodesign: Visa criar produtos, embalagens, serviços e processos ecológicos eficientes, com o objetivo de agredir menos o meio ambiente, sem descuidar de termos como segurança e saúde, ou seja, não adianta criar um produto sustentável que faça mal ao ser humano, ou que não ofereça a segurança necessária para o consumo.
} 
são avaliados apenas custos e produtividade, quanto à questão ambiental, existe apenas a preocupação em cumprir leis.

Apesar de que $50 \%$ dos gestores afirmarem que a legislação ajuda na melhora do funcionamento e no aproveitamento da matéria-prima é significativo o percentual (40\%) de gestores que afirmam que apesar da legislação ajudar no melhoramento do funcionamento não contribui no aproveitamento da matéria-prima. Portanto, uma parcela expressiva das empresas pesquisadas acredita que a legislação é um empecilho para seu funcionamento.

\section{CONCLUSÃO}

Historicamente, para sobreviver, o homem acabou afetando de uma ou de outra forma o ambiente natural, destruindo parte das matas para construir seu lar e cultivar alimentos. Apesar de viverem em harmonia por muitos anos, com o passar do tempo e a necessidade do desenvolvimento, o homem com suas inúmeras descobertas em todos os campos da ciência, atingiu uma incrível capacidade de produção que como consequência gerou fatores que já extinguiram muitos seres e que podem levar o homem à extinção.

De fato, o desenvolvimento é necessário e traz muitos benefícios, como a criação de produtos e serviços que atendem as necessidades das pessoas, porém não pode ser cobiçado a qualquer custo, as questões ambientais e sociais devem ser avaliadas.

O estudo evidenciou que existe uma preocupação por parte das empresas quanto ao pleno cumprimento da legislação ambiental pertinente, porém apresentam pouco conhecimento, interesse e ações para o desenvolvimento sustentável. É expressivo o número de empresas que não possuem assessoria ambiental; nenhuma empresa tem ou busca a certificação da ISO 14000; apenas uma empresa tem plantio próprio de árvores e utiliza energia alternativa para o funcionamento das máquinas; os resíduos são pouco reaproveitados alternativamente como forma de energia e uso em subprodutos; existem poucos cuidados quanto à poluição do ar; cuidados essenciais não são adotados pela maioria das empresas, como a classificação dos produtos na armazenagem que além de facilitar a sua localização evita que o produto fique esquecido tornando-se obsoleto. $80 \%$ das empresas não utilizam o marketing verde e $70 \%$ não promovem ou participam de projetos ambientais e além de tudo isso, as questões ambientais não são consideradas quando é realizado algum investimento na organização, apenas custos e produtividade são avaliados.

Pelo fato das questões ambientais e o desenvolvimento sustentável das organizações serem um tema de grande relevância, sugere-se que sejam realizados mais estudos nesta área, nos diferentes setores da economia, pois são necessários, profissionais que demonstram interesse e preocupação com estes temas. Outra sugestão para futuros estudos é realizar uma análise comparativa entre o polo moveleiro da Região Noroeste do Rio Grande do Sul, que está em constante crescimento, com o polo moveleiro de Bento Gonçalves, considerado o maior do país, avaliando o desenvolvimento sustentável. 
Buscar a redução do desperdício, otimização do uso da matéria prima, redução do consumo de energia e água é muito mais que reduzir os custos, é mostrar um compromisso com as presentes e futuras gerações e com a conservação do planeta.

O consumismo exagerado nos faz refletir de que é preciso reciclar o conceito de lixo e resíduos, é preciso transformá-los em dinheiro, reciclar o que aparentemente não pode mais ser utilizado e dar a ele um destino sustentável.

Para isso, as organizações precisam entender que para atingir o desenvolvimento é preciso crescer com sustentabilidade, estar em harmonia com o meio ambiente e com a comunidade. O retorno de seus investimentos será maior a partir do momento em que proporcionarão boas condições de trabalho aos seus funcionários, qualidade de vida para a comunidade em geral, atuando com compromisso ambiental e social.

\section{REFERÊNCIAS}

Abimóvel. História Moveleira. Disponível em: http://arquivopdf.sebrae.com.br/setor/madeira-emoveis/o-setor/historia-moveleira. Acesso em 01/03/2013.

Albuquerque, J. de L. (Org.) (2009). Gestão ambiental e responsabilidade social: conceitos, ferramentas e aplicações. São Paulo: Atlas.

Alemanha pode ter $100 \%$ de energia renovável. Disponível em: http://exame.abril.com.br/meioambiente-e-energia/noticias/alemanha-pode-ter-100-energia-renovavel-2050-576750. Acesso em 11/06/2013.

De Andrade, M. M. (2007). Introdução a metodologia do trabalho científico. 8a ed. São Paulo: Atlas.

De Andrade, R. O. B.; Carvalho, A. B. de; Tachizawa, T. (2006). Gestão ambiental: enfoque estratégico aplicado ao desenvolvimento sustentável. SÃO PAULO: Makron Books.

Barbieri, J. C. (2007). Gestão Ambiental Empresarial, conceitos, modelos e instrumentos. São Paulo: Ed. Saraiva.

Centro Gestor De Inovação Moveleiro http://www.cgimoveis.com.br/economia/movergs-cgimoveleiro-e-ucs-divulgam-dados-sobre-perfil-socio-economico-e-gerencial-do-setormoveleiro-gaucho. Acesso em 20/04/2013.

Com novos parques, RS tenta virar líder em geração de energia eólica. Disponível em: http://g1.globo.com/rs/rio-grande-do-sul/noticia/2013/04/com-novos-parques-rs-tentavirar-lider-em-geracao-de-energia-eolica.html. Acesso em 11/06/2013.

Cunha, S. B. da; Guerra, A. J. T. (2010). Avaliação e perícia Ambiental. Rio de Janeiro: Bertrand Brasil.

Dias, R. (2007). Gestão Ambiental, Responsabilidade Social e Sustentabilidade. São Paulo: Ed. Atlas S.A. 
Do lixo ao luxo. $\quad$ Disponível http://www.istoedinheiro.com.br/noticias/26591_DO+LIXO+AO+LUCRO. Acesso em $11 / 06 / 2013$.

Fachin, O. (2001). Fundamentos de Metodologia. São Paulo: Saraiva.

FEPAM suspende restrições temporariamente. Disponível em: http://www.movergs.com.br/noticias/fepam-suspende-restricoes-temporariamente-. Acesso em 11/06/2012.

Ferrari, J. $\quad$ S. Consumismo. Disponível em: http://www.brasilescola.com/psicologia/consumismo.htm. Acesso em 23/05/2013.

Güllich, R. I.; Lovato, A.; Evangelista, M. dos S. (2007). Metodologia da Pesquisa: normas para apresentação de trabalhos: redação, formatação e editoração. Três de Maio: Ed. SETREM.

Harrington, H. J. \& Knight, A. (2001). A Implementação da ISO 14000: como atualizar o SGA com eficácia. Tradução de Fernanda Góes Barroso, Jerusa Gonçalves de Araújo; revisão técnica Luis César G. de Araújo. São Paulo: Atlas.

Jung, C. F. (1998). Metodologia para pesquisa e desenvolvimento. Rio de Janeiro: Axcel.

Lei de Crimes Ambientais - Lei no 9605/98 / Lei no 9.605, de 12 de fevereiro de 1998. Disponível em: $\quad$ http://www.jusbrasil.com.br/legislacao/104091/lei-de-crimes-ambientais-lei-960598\#art46. Acesso em 11/06/2013.

Leis e Decretos. Disponível em: http://www.proamb.com.br/leis_decretos/portaria_009.pdf. Acesso em 11/06/2013.

Lei no 9.921, de 27 de julho de 1993. Disponível em: http://www.emater.tche.br/site/br/arquivos/area/legislacao/estadual/le-lei9921.pdf. Acesso em 11/06/2013.

Lustosa, M. C.; May, P. M.; Vinha, V. da. (2003). Economia do meio ambiente. Rio de Janeiro: Ed. Elsevier.

Marca

de

Credenciamento

Inmetro.

http://www.inmetro.gov.br/gestao14001/ResultCatalogo.asp?Chamador=INMETRO14\&Inici o=1. Acesso em 20/04/2012.

MOVERGS/IEMI (Brasil Móveis 2012) - SINDIMÒVEIS/SEFAZ-RS. Disponível em: http://www.movergs.com.br/arquivos/apresentacao_movergs_para_o_site.pdf. Acesso em 01/03/2013.

$\begin{array}{llllll}N R & 25 & - & \text { Resíduos } & \text { Industriais. } & \text { Disponível }\end{array}$ http://portal.mte.gov.br/data/files/8A7C816A31B027B80131B4F9B2F25242/nr25.pdf. Acesso em 11/06/2013.

Philippi, L. S. (2001). A Construção do Desenvolvimento Sustentável. Educação Ambiental Questões Ambientais - Conceitos, História, Problemas e Alternativa. 2a Ed. Brasília: Ministério do Meio Ambiente. 
Pinheiro, J. M. dos S. (2010). Da iniciação científica ao TCC uma abordagem para os cursos da Tecnologia. Rio de Janeiro: Ed. Ciência Moderna Ltda.

Romeiro, A. R. (2012). Desenvolvimento sustentável: uma perspectiva econômico-ecológica. São Paulo. ISSN 0103-4014.

Smaneoto, C. (2012). A responsabilidade socioambiental e a sustentabilidade como nova fronteira para o cooperativismo agropecuário. Dissertação: UNIJUí, ljuí.

Seiffert, M. E. B. (2011). ISO 14001, Sistemas de Gestão Ambiental, Implantação objetiva e econômica. 4 ed. São Paulo: Ed. Atlas.

Da Veiga, J. E. (2010). Desenvolvimento Sustentável: o desafio do século XXI. Rio de Janeiro: Ed. Garamond.

Office Excel. Disponível em: http://office.microsoft.com/pt-br/novice/o-que-e-o-excelHA010265948. aspx, Acesso em 12/10/2012. 